\title{
Antioxidant Activity and Phenolic Content of Apple Cider
}

\author{
Nilgün Havva Budak ${ }^{*}$, Filiz Ozçelik ${ }^{2}$, Zeynep Banu Güzel-Seydim³ \\ ${ }^{1}$ Department of Food Processing, Eğirdir Vocational School, Süleyman Demirel University, 32500 Eğirdir/Isparta, Turkey \\ ${ }^{2}$ Department of Food Engineering, Faculty of Engineering, Ankara University, 06100 Ankara, Turkey \\ ${ }^{3}$ Department of Food Engineering, Faculty of Engineering, Süleyman Demirel University, 32260 Isparta, Turkey
}

A R T I C LE INFO

Article history:

Received 03 December 2014

Accepted 10 February 2015

Available online, ISSN: 2148-127X

Keywords:

Apple cider

Chlorogenic acid

Maceration

ORAC

TEAC

${ }^{*}$ Corresponding Author:

E-mail: nilgunbudak@sdu.edu.tr
A B S T R A C T

Fruit and vegetables are an important component of a healthy diet and the main antioxidant suppliers in the human diet. Consumption of foods derived from fruits and vegetables is also essential; fruit juices, ciders, wines, and vinegars also contain significant amounts of polyphenolic compounds. The aim of the study was to determine the effect maceration of antioxidant activity and phenolic content of apple cider. Red delicious apples were used to produce natural apple cider with and without inclusion of maceration. Samples were taken from fresh red apple juice, macerated samples and apple cider. Apple cider (maceration was applied) (CAM) had the highest total phenolic content, chlorogenic acid, ORAC and TEAC levels. Chlorogenic acid was the dominant phenolic substance in apple juice and cider samples and chlorogenic acid was increased with maceration process.

\section{Introduction}

Fruit and vegetables are an important component of a healthy diet and, if consumed daily in sufficient amounts, could help prevent major diseases such as cardiovascular diseases (CVDs) and certain cancers. Noncommunicable diseases (NCDs), especially cardiovascular diseases (CVDs), cancer, obesity and diabetes, currently kill more people every year than any other cause of death. The recent Joint FAO/WHO Expert Consultation on diet, nutrition and the prevention of chronic diseases, recommended the intake of a minimum of $400 \mathrm{~g}$ of fruit and vegetables per day (excluding potatoes and other starchy plant) for the prevention of NCDs as well as for the prevention and alleviation of several micronutrient deficiencies, especially in less developed countries (WHO, 2003).

Dietary intake of natural antioxidants has recently received increased attention due to the epidemiological evidence that correlates a regular intake of these products with protection against several diseases (Hertog et al., 1995). Fruits and vegetables are the main antioxidant suppliers in the human diet. Among them, apple is important not only for its high antioxidant content, but also for its acceptance among the general consumer population. Vinson et al. (2001) reported that $22 \%$ of the fruit phenolics consumed in the United States came from apple. Eberhardt et al. (2000) found that $100 \mathrm{~g}$ of fresh apples have an antioxidant activity equivalent to $1500 \mathrm{mg}$ of vitamin $\mathrm{C}$, and more important, that apple phenolic extracts inhibited proliferation of a human cancer cell line. The major antioxidants present in apple are polyphenols, which include phenolic acids (chlorogenic, cinammic, gallic acid, etc.) and flavonoids (catechin, quercetin, quercetin glycosides, etc.). Apple and apple products (juice, cider, vinegar) are commonly consumed worldwide. Apple polyphenols contain mainly polyphenolic acid derivatives and other flavonoids. Generally, these polyphenols are distributed in the whole fruit, with higher concentrations present in the peel rather than in the flesh (Wolfe et al., 2003). The complexation and antioxidant activity of the major apple polyphenols: Chlorogenic Acid (CA), Rutin (Rt) and Quercetin (Qc) with b-cyclodextrin (b-CD) were studied, by fluorescence spectroscopy and Ferric Reducing/Antioxidant Power Assay (FRAP) techniques (Alvarez-Parrilla et al., 2005). Budak et al. (2011) reported that chlorogenic acid is also commonly in apple cider vinegar.

The aim of the study was to determine the effect of maceration on antioxidant activity and phenolic content level of ciders derived from red delicious apples during cider production. Red delicious apples were used to produce natural apple cider with and without inclusion of maceration. 


\section{Material and Methods}

\section{Material}

"Red Delicious" apple was harvested in Gelendost, Isparta, and appropriately transported to Fermentation Laboratory in the Süleyman Demirel University Gelendost Vocational School (Isparta, Turkey).

\section{Apple Cider Production}

"Red delicious" apples were used to make natural apple cider to determine the effects of maceration. Flow scheme of apple cider production methods are presented in Figure 1. The samples were named as apple juice (AJ), apple juice sample taken after maceration (ASM), apple juice after fermentation without maceration sample (AS), apple cider (with maceration) (CAM) and apple cider sample (without maceration) (CA).

Briefly, after red apples were broken into pieces maceration was carried out during seven days. Addition of $10 \%$ pomace was used in the maceration step to increase the polyphenolic contents. Apple cider was obtained after processing apple juice was fermented for two months.

\section{Compositional Analysis}

Total titratable acidity, density and total ash of apple juice and apple cider samples were determined according to AOAC methods (1992). Total sugar in apple juice and maceration samples were analyzed according to the Luff Schoorl methods (AOAC 1990). Water soluble solid (Brix) was measured with Abbe refractometer (Bellingham Stanley Limit 60/70 Refractometer, England). Ethanol content was determined with alcoholmeter (Dujardin-Salleron, France).

\section{Total Antioxidant Activity}

Total phenolic content: Total phenolic contents of the samples were determined according to Folin-Ciocalteu method using gallic acid as a standard (Singleton and Rossi, 1965; Singleton et al., 1999). After addition of Folin-Ciocalteu reagent to the sample solution it was allowed to react for $6 \mathrm{~min}$. Reaction was stopped with using $1.50 \mathrm{~mL}$ of $20 \%$ sodium carbonate. The extracts were oxidized with Folin-Ciocalteu reagent, and the reaction was neutralized with sodium carbonate. The absorbance of the resulting blue colour was developed in $120 \mathrm{~min}$ in a dark place, and the absorbance was determined at $760 \mathrm{~nm}$ using a spectrophotometer (Shimadzu Scientific Instruments, Inc., Tokyo, Japan). The measurement was calculated using a standard curve of gallic acid and expressed as milligrams of gallic acid equivalents $(\mathrm{GAE}) \mathrm{L}^{-1}$.

2,2'-azinobis (3-ethlybenzthiazoline)-6-sulfonic acid (ABTS) Assay: 2,2'-azinobis (3-ethlybenzthiazolin-6sulfonic acid) diammonium salt $\left(\mathrm{ABTS}^{+}\right)$radical cation was prepared by reacting $7 \mathrm{mM}$ ABTS stock solution with $2.45 \mathrm{mM}$ potassium persulfate (Re et al., 1999). $\mathrm{ABTS}^{+}$ inhibition against Trolox (6-hydroxy-2, 5, 7, 8tetramethylchroman-2-carboxylic acid) was spectrophotometrically measured (Seeram et al., 2005).

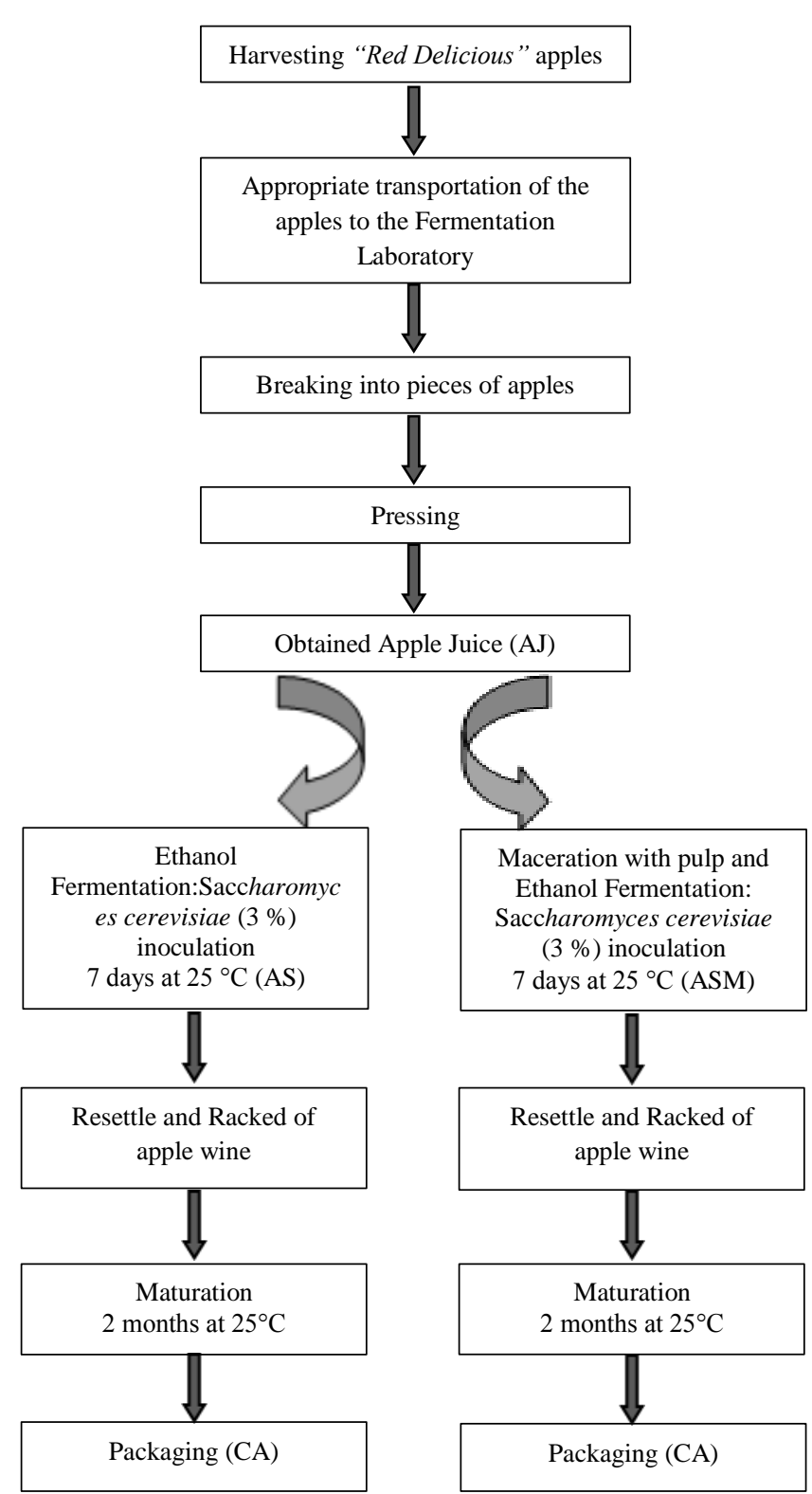

Figure 1 Flow chart of apple cider (maceration was applied and was not applied)

The concentration of the resulting blue-green ABTS radical solution was adjusted to an absorbance of $0.700 \pm$ 0.020 at $734 \mathrm{~nm}$ in a spectrophotometer (Shimadzu Scientific Instruments, Inc., Tokyo, Japan). TEAC values of samples were calculated from the Trolox standard curve and expressed as Trolox equivalents (in $\mu \mathrm{mol} / \mathrm{ml}$ of sample).

Oxygen Radical Absorbance Capacity (ORAC) Assay: All samples were analysis using the Oxygen Radical Absorbance Capacity (ORAC) (Wu et al., 2008). The samples were appropriately diluted with phosphate buffer (pH 7.4) for ORAC analysis. An aliquot $(25 \mu \mathrm{L})$ of the diluted sample, blank (phosphate buffer) or Trolox calibration solutions were added to a black, clear-bottom triplicate well in 96 well bottom reading microplate. After the addition of $150 \mu \mathrm{M}$ flourescein stock solution $(0,004$ $\mu \mathrm{M})$ to each well the microplate was incubated at $37^{\circ} \mathrm{C}$

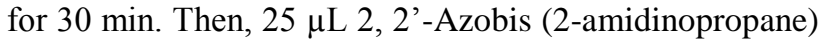


dihydrochloride (AAPH) solution $(153 \mathrm{mM})$ was added to start the reaction. The microplate reader was programmed to record the fluorescence reading with an excitationemission wavelength of $485-520 \mathrm{~nm}$ using software Gen $5^{\mathrm{TM}}$. Antioxidant activity was kinetically measured with Biotek Synergy ${ }^{\mathrm{TM}}$ HT Multi-Detection Microplate Reader (Winooski, Vermont, USA).

Quantification of Phenolics by High Performance Liquid Chromatography: Phenolic compounds were evaluated by reversed-phase high performance liquid chromatography (RP-HPLC, Shimadzu Scientific Instruments, Kyoto, Japan). Phenolic compositions of the extracts were determined by a modified method of Schulz et al. (2001). Detection and quantification were carried out with a LC-10ADvp pump, SIL-10ADvp auto sampler, a Diode Array Detector, a CTO-10Avp column heater, SCL-10Avp system controller and DGU-14A degasser (Shimadzu Scientific Instruments, Kyoto, Japan). Separations were conducted at $30^{\circ} \mathrm{C}$ on Agilent ${ }^{\circledR}$ Eclipse XDB C-18 reversed-phase column (250 mm x $4.6 \mathrm{~mm}$ length, $5 \mu \mathrm{m}$ particle size). The mobile phases were $\mathrm{A}: 3.0 \%$ acetic acid in distilled water and $\mathrm{B}$ : methanol. Flow rate was $0.8 \mathrm{~mL} / \mathrm{min}$. Gallic acid, catechin, caffeic acid, chlorogenic acid, p-coumaric acid, ferulic acid, rutin, resveratrol and syringic acid were used as standard. Identification and quantitative analysis were done by comparison with standards.

\section{Statistics}

All data were reported as the mean and standard error. Results analyzed by using SPSS for Windows (version 17.0, SPSS Inc.). Apple cider production was repeated three times. Values represent means of triplicate repetition with parallels. The significance was established at $\mathrm{P}<0.05$.

\section{Results and Discussion}

\section{Composition analysis}

Total titratable acidity, density, Brix, total ash total sugar and alcohol in apple juices and apple cider samples are reported in Table 1. Total titratable acidity was increased during ethanol fermentation. Especially, total titratable acidity in the sample taken from maceration was significantly higher than the sample that maceration was not applied $(\mathrm{P}<0.05)$. Total titratable acidity values in Cashew juice and Golden Delicious fresh apple juice samples were $2.4 \mathrm{~g} / \mathrm{L}$ and $2.88 \mathrm{~g} \mathrm{MA} / \mathrm{L}$, respectively (Mohanty et al., 2006; Suárez-Jacobo et al., 2011). Density of the samples varied between $0.9987-1.0517$ $\mathrm{g} / \mathrm{cm}^{3}$. Density and Brix values were significantly decreased during alcohol fermentation due to the conversion of sugar to ethanol $(\mathrm{P}<0.05)$. Budak and Güzel-Seydim (2010) explained that total solids and Brix of samples significantly decreased after maceration due to pressing, resettling and racking during grape wine production. Brix of Cashew apple wine was found to be $2.0 \%$ (Mohanty et al., 2006). In our study, brix of the apple cider sample was $3.83 \%$. Alcohol contents of apple cider samples were between 5.40-6.10\%. The total sugar contents were 144.24, 85.77, 95.56 g/L in AS, ASM and
AS, respectively. Total sugar content also decreased due to the ethanol fermentation by Saccharomyces cerevisae (Budak and Güzel-Seydim, 2010).

\section{Total Antioxidant Activity}

Total phenolic content, TEAC and ORAC results express the total antioxidant activity in the samples. Total phenolic content (mg/L), TEAC (mmol/L) and ORAC $(\mu \mathrm{mol} / \mathrm{mL})$ values of samples are presented in Figures 2 and 3, respectively. AJ sample had the lowest total phenolic content whereas CAM sample had the highest total phenolic content among the samples $(\mathrm{P}<0.05)$. Seeram et al. (2008) reported that TEAC and ORAC value of apple juice samples ranged between 2.5$6.2 \mu \mathrm{mol}$ of $\mathrm{TE} / \mathrm{mL}$ and $2.7-4.3 \mu \mathrm{mol} / \mathrm{mL}$, respectively. Total phenolic contents of AS and CAM samples were $459.31 \mathrm{mg} / \mathrm{L}$ and $1026.74 \mathrm{mg} / \mathrm{L}$, respectively (Figure 3). Lachman et al. (2006) determined that total phenolic content of apple juice samples obtained from different varieties were between 760.03- $1343 \mathrm{mg} / \mathrm{L}$. In our study, total phenolic content of ASM and AS samples were 777.83 and $733.61 \mathrm{mg} / \mathrm{L}$. Contents of TEAC, ORAC and total phenolic content in CAM sample was the highest in all samples. TEAC and ORAC values of CAM sample were $13.27 \mathrm{mmol} / \mathrm{L}$ and $9.84 \mu \mathrm{mol} \mathrm{TE} / \mathrm{mL}$, respectively. ORAC values of apple cider samples were the highest in all samples. Especially, ORAC values of CAM sample was the highest in all samples (Figure 3). Antioxidant activities of macerated juice samples and ciders were higher than the samples that maceration was not applied.

\section{Phenolic Substances}

Gallic acid, catechin, epicatechin, caffeic acid, chlorogenic acid, and p-coumaric acid were detected in apple juice and apple cider samples (Table 2). Contents of catechin, epicatechin, and chlorogenic acid were identified in all samples. Gallic acid only was detected in apple juice sample. The content of catechin in CAM sample was significantly higher than CA sample $(\mathrm{P}<0.05)$. The amount of epicatechin was $4.63 \mathrm{mg} / \mathrm{L}$ in CAM sample while CA sample contained $3.33 \mathrm{mg} / \mathrm{L}$ $(\mathrm{P}<0.05)$. Chlorogenic acid was the dominant phenolic substance in apple juice samples; especially, ASM and CAM samples had the highest content of chlorogenic acid $(\mathrm{P}<0.05)$. Chlorogenic acid significantly increased with maceration. p-Coumaric acid contents of apple cider samples ranged between 0.03 and $0.04 \mathrm{mg} / \mathrm{L}$. AlvarezParilla et al. (2005) reported that chlorogenic acid is one of the important apple polyphenols. Chlorogenic acid, catechin, epicatechin, caffeic acid were high concentrations in apple cider that maceration was applied. Therefore, maceration process was important for the concentrations of the polyphenolic compounds. Polyphenolic content (chlorogenic acid, catechin, epicatechin and caffeic acid) of CAM sample had the highest values similar to antioxidant activity of CAM sample (total phenolic content, TEAC and ORAC contents). It has been reported that wine vinegars show an antioxidant capacity that is correlated with their polyphenolic content (Dávalos et al., 2005). In this study, phenolic substances were increased by fermentation. 
Table1 Composition Analysis of Samples

\begin{tabular}{l|cccccc}
\hline Samples & TTA $^{1}$ Total & Density $\left(\mathrm{g} / \mathrm{cm}^{3}\right)$ & Brix $(\%)$ & Total sugar $(\mathrm{g} / \mathrm{L})$ & Total Ash $(\mathrm{g} / \mathrm{L})$ & Ethanol $(\mathrm{v} / \mathrm{v})$ \\
\hline $\mathrm{AJ} 2$ & $1.9 \pm 0.04^{\mathrm{a}}$ & $1.0517 \pm 0.00^{\mathrm{a}}$ & $11.67 \pm 1.42^{\mathrm{a}}$ & $144.24 \pm 1.11^{\mathrm{a}}$ & $1.9 \pm 0.01^{\mathrm{a}}$ & - \\
$\mathrm{ASM}^{3}$ & $2.3 \pm 0.03^{\mathrm{a}}$ & $0.9999 \pm 0.00^{\mathrm{b}}$ & $4.58 \pm 0.71^{\mathrm{b}}$ & $85.77 \pm 3.26^{\mathrm{b}}$ & $1.7 \pm 0.02^{\mathrm{a}}$ & $3.10 \pm 0.14^{\mathrm{b}}$ \\
$\mathrm{AS}^{4}$ & $3.7 \pm 0.06^{\mathrm{c}}$ & $1.0014 \pm 0.00^{\mathrm{c}}$ & $5.33 \pm 0.34^{\mathrm{b}}$ & $95.56 \pm 0.41^{\mathrm{b}}$ & $1.7 \pm 0.00^{\mathrm{b}}$ & $2.90 \pm 0.12^{\mathrm{b}}$ \\
$\mathrm{CAM}^{5}$ & $2.3 \pm 0.03^{\mathrm{a}}$ & $0.9987 \pm 0.00^{\mathrm{b}}$ & $3.83 \pm 0.83^{\mathrm{b}}$ & - & $1.9 \pm 0.01^{\mathrm{a}}$ & $6.10 \pm 0.15^{\mathrm{a}}$ \\
$\mathrm{CA}^{6}$ & $3.5 \pm 0.04^{\mathrm{c}}$ & $0.9987 \pm 0.00^{\mathrm{c}}$ & $3.83 \pm 0.13^{\mathrm{b}}$ & - & $1.8 \pm 0.01^{\mathrm{b}}$ & $5.40 \pm 0.11^{\mathrm{b}}$ \\
\hline
\end{tabular}

${ }^{1}$ TTA: Total Titratable Acidity (g/L), ${ }^{2} \mathrm{AJ}$ : Apple juice, ${ }^{3} \mathrm{ASM}$ : Apple juice taken after maceration, ${ }^{4}$ AS: Apple juice without maceration sample,

${ }^{5} \mathrm{CAM}$ : Apple cider (maceration was applied), ${ }^{6} \mathrm{CA}$ : Apple cider sample (maceration was not applied)

Table 2 Phenolic Compounds of Samples

\begin{tabular}{l|cccccc}
\hline Samples & $\begin{array}{c}\text { Gallic acid } \\
(\mathrm{mg} / \mathrm{L})\end{array}$ & $\begin{array}{c}\text { Catechin } \\
(\mathrm{mg} / \mathrm{L})\end{array}$ & $\begin{array}{c}\text { Epicatechin } \\
(\mathrm{mg} / \mathrm{L})\end{array}$ & $\begin{array}{c}\text { Caffeic acid } \\
(\mathrm{mg} / \mathrm{L})\end{array}$ & $\begin{array}{c}\text { Chlorogenic acid } \\
(\mathrm{mg} / \mathrm{L})\end{array}$ & $\begin{array}{c}\text { p-Coumaric acid } \\
(\mathrm{mg} / \mathrm{L})\end{array}$ \\
\hline $\mathrm{AJ}^{1}$ & $0.43 \pm 0.06^{\mathrm{b}}$ & $0.50 \pm 0.00^{\mathrm{c}}$ & $1.60 \pm 0.10^{\mathrm{bc}}$ & - & $12.26 \pm 3.37^{\mathrm{c}}$ & - \\
$\mathrm{ASM}^{2}$ & - & $1.47 \pm 0.29^{\mathrm{b}}$ & $3.50 \pm 0.78^{\mathrm{a}}$ & $0.46 \pm 0.24^{\mathrm{ab}}$ & $18.53 \pm 4.06^{\mathrm{a}}$ & - \\
$\mathrm{AS}^{3}$ & - & $1.56 \pm 0.13^{\mathrm{b}}$ & $4.13 \pm 0.36^{\mathrm{a}}$ & - & $17.86 \pm 0.60^{\mathrm{b}}$ & $0.05 \pm 0.01^{\mathrm{b}}$ \\
$\mathrm{CAM}^{4}$ & - & $2.13 \pm 0.28^{\mathrm{a}}$ & $4.63 \pm 1.20^{\mathrm{a}}$ & $0.96 \pm 0.08^{\mathrm{a}}$ & $24.13 \pm 3.46^{\mathrm{a}}$ & $0.03 \pm 0.01^{\mathrm{b}}$ \\
$\mathrm{CA}^{5}$ & - & $1.46 \pm 0.23^{\mathrm{b}}$ & $3.33 \pm 0.23^{\mathrm{ab}}$ & $0.75 \pm 0.05^{\mathrm{a}}$ & $16.50 \pm 2.27^{\mathrm{b}}$ & $0.04 \pm 0.00^{\mathrm{b}}$ \\
\hline
\end{tabular}

${ }^{1}$ AJ: Apple juice, ${ }^{2}$ ASM: Apple juice taken after maceration, ${ }^{3} \mathrm{AS}$ : Apple juice without maceration sample, ${ }^{4} \mathrm{CAM}$ : Apple cider (maceration was applied), ${ }^{5} \mathrm{CA}$ : Apple cider sample (maceration was not applied)

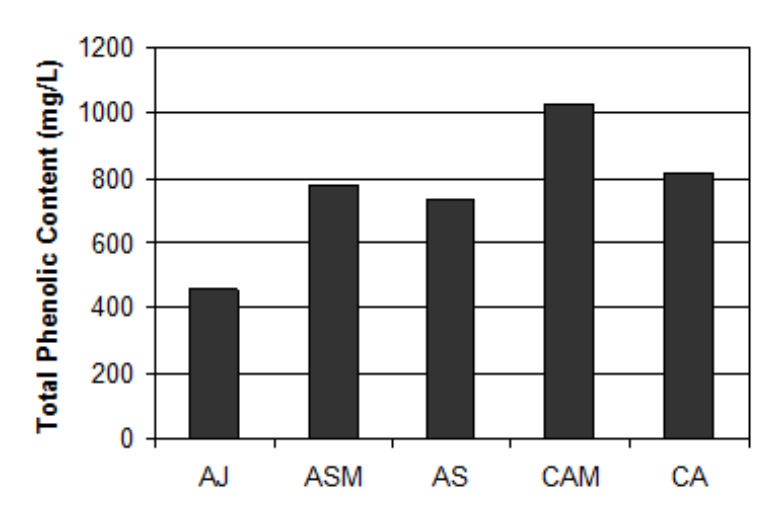

Figure 2 Total Phenolic Content of Apple Juices and Cider Samples AJ: Apple juice, ASM: Apple juice taken after maceration, AS: Apple juice without maceration sample, CAM: Apple cider (maceration was applied) , CA:Apple cider sample (maceration was not applied)

\section{Conclusion}

This is the first report confirming that maceration had positive effects on bioactive components of apple cider. Results of this study showed that polyphenolic compounds and antioxidant activity significantly increased in maceration process. Antioxidant activity of apple cider (maceration included) sample was higher than that of apple cider sample (maceration was not applied). Chlorogenic acid was the dominant phenolic substance in apple juice samples while chlorogenic acid increased during maceration. Chlorogenic acid, catechin, epicatechin, caffeic acid contents of macerated apple cider were in high concentrations. Therefore, inclusion of maceration in process would be important for concentration of bioactive compounds.

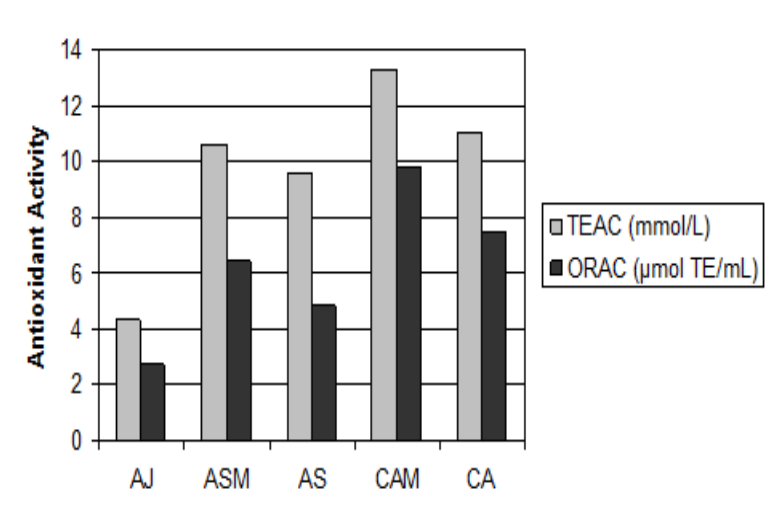

Figure 3 Antioxidant activity of samples by ABTS (TEAC) assay and ORAC assay AJ: Apple juice, ASM: Apple juice taken after maceration, AS: Apple juice without maceration sample, CAM: Apple cider (maceration was applied) , CA: Apple cider sample (maceration was not applied)

\section{References}

Alvarez-Parrilla E, Rosa LDL, Torresrivas F, Rodrigo-Garcia J, Gonzalez'Lez-Aguilar GA. 2005. Complexation of Apple Antioxidants: Chlorogenic Acid, Quercetin and Rutin by bCyclodextrin (b-CD). J Incl Phenom Macro 53:121-129.

AOAC. 1990. Association of Official Analytical Chemists. Official Methods of Analysis, 13th edition. Washington DC.

AOAC. 1992. Association of Official Analytical Chemists. Official Methods of Analysis, 15th edition. Washington DC.

Budak HN, Güzel-Seydim Z. 2010. Antioxidant activity and phenolic content of wine vinegars produced by two different techniques. J Sci Food Agric, 90: 2021-2026.

Caponia F, Alloggio V, Gomes T. 1999. Phenolic compounds of virgin olive oil: influence of paste preparation techniques. Food Chem 63: 203-209.

Eberhardt MV, Lee CY, Liu RH. 2000. Antioxidant activity of fresh apples. Nature. 405: 903-4. 
Hertog MG, Kromhout D, Aravanis C, Blackburn H, Buzina R, Filanza F, Giampaoli S, Jansen A, Menotti A, Nedeljkovic S. 1995. Flavonoid intake and long-term risk of coronary heart disease and cancer in the seven countries study. Arch. Internal Med., 155: 281-286.

Lachman J, Šulc M, Sus J, Pavlíková O. 2006. Polyphenol content and antiradical activity in different apple varieties. Hort Sci 33: 95-102.

Mohanty S, Ray P, Swain MR, Ray RC. 2006. Fermentation of Cashew (Anacardium Occidentale L.) "Apple" into wine. J Food Process Pres, 30: 314-322.

Re R, Pellegrini N, Proteggente A, Pannala A, Yang M, Rice-Evans C. 1999. Antioxidant activity applying an improved ABTS radical cation decolorization assay. Free Radic Bio Med 26: 1231-1237.

Seeram N, Adams L, Henning S. 2005. In vitro antiproliferative. apoptotic and antioxidant activities of punicalagins. ellagic acid and a total pomegranate tannin extract are enhanced in combination with other polyphenols as found in pomegranate juice. J Nutr Biochem, 16: 360-367.
Singleton VL, Rossi JA. 1965. Colorimetry of total phenolics with phosphomolbdic phosphotungstic acid reagents. Am J Enol Vitic, 16: 144-158.

Singleton VL, Orthofer R, Lamuela-Raventos, RM. 1999. Analysis of total phenols and other oxidation substrates and antioxidants by means of Folin-Ciocalteu reagent. Method Enzymol, 99: $152-178$.

Suárez-Jacobo A, Rüfer CE, Gervilla R, Guamis B, Roig-Sagués, $\mathrm{AX}$, Saldo J. 2011. Influence of ultra-high pressure homogenisation on antioxidant capacity, polyphenol and vitamin content of clear apple juice. Food Chem., 127: 447-454.

Vinson JA, Su X, Zubik L, Bose P. 2001. Phenol antioxidant quantity and quality in foods: fruits. J Agric Food Chem., 49: 5315-21.

WHO. 2003. Diet, nutrition and the prevention of chronic diseases. Report of a Joint FAO/WHO Expert Consultation. Geneva, World Health Organization, (WHO Technical Report Series, No. 916).

Wolfe K, Wu X, Liu RH. 2003. Antioxidant activity of apple peels. J Agric Food Chem, 51: 609-614.

Wu C, Duckett SK, Neel JPS, Fontenot JP, Clapham WM. 2008. Influence of finishing systems on hydrophilic and lipophilic oxygen radical absorbance capacity (ORAC) in beef. Meat Sci., 80: 662-667. 